\title{
INDIGO DALAM NOVEL SUPERNOVA AKAR KARYA DEE LESTARI: KAJIAN PSIKOLOGI SASTRA
}

\author{
Erna Rakhmawati \\ SMKN I Kalitengah Lamongan \\ HP 085850425679; Poe-el ernarakhmawati02@gmail.com
}

\begin{abstract}
Abstrak: Penelitian yang berjudul "Indigo dalamNovel Supernova Akar karya Dee Lestari :Tinjauan Psikologi Sastra” berlatar belakang Banyak fenomena indigo di masyarakat dan banyak karya sastra tentang indigo, sehingga menarik untuk dikaji. Tujuan penelitian ini pertama untuk mengetahui gambaran kemampuan indigo yang dialami tokoh, kedua untuk mengetahui penyebab indigo yang dialami tokoh, dan ketiga untuk mengetahui jenis indigo yang dialami oleh tokoh dalam novel Supernova Akar. Penelitian ini termasuk penelitian kualitatif deskriptif dengan teknik analisis data menggunakan tekstual analisis atau analisis teks. Subyek dari penelitian ini adalah tokoh dalam novel Supernova Akar.Hasil dari penelitian ini yang ternarasikan oleh Dee Lestari adalah penulis menemukan bahwa gambaran kemampuan indigo yang dimiliki tokoh adalah;1) levitasi, 2) procegnition, 3) psicometri, 4) teleportasi, dan 5) clayrvoyance. Penyebab indigo yang dialami tokoh dalam novel Supernova Akar adalah; 1) anugrah atau karomah dari Tuhan,2) dari keturunan, dan 3) dari latihan. Jenis indigo yang dialami oleh tokoh dalam novel Supernova akar adalah ;1) humanis dan 2) artis.
\end{abstract}

Kata kunci: indigo, Supernova Akar, psikologi

Abstract: The background of this research is many indigo events in the community and many indigo literary works. Indigo research in the "Indigo dalam Novel Supernova Akar Karya Dee Lestari:Tinjauan Psikologi Sastra," first aims to find the description of the indigo abilities experienced by the characters, secodly to find the causes of indigo experienced by characters, and thirdly to find out the type of indigo experienced by characters in the Supernova Akar. The research includes qualitative descriptive research on data analysis techniques using textual analysis or text analysis. The subject of this study is a character in the Supernova Akar. The result of research that is narated by Dee lestari source are; 1)levitasi, 2) procegnition, 30 psicometri, 4) teleportasi, and 5) clayvoyance. Indigo causes experienced by characters in the Supernova Akar are; 1) a gift from God, 2) from offspring, and from training. The type of indigo experienced by characters in the Supernova Akar are; humanis and artis.

Keyword: indigo, Supernova Akar, psicology

PENDAHULUAN

Dunia ini banyak terisi hal-hal aneh dan menakjubkan. Di setiap detik pada setiap hari, dunia ini dipenuhi kejadiankejadian yang beraneka rupa. Tingkah laku inilah yang kemudian mewujudkan beragam fenomena, mewujudkan beragam karya, salah satunya adalah bahasa.Keberadaan manusia sebagai makhluk hidup dalam proses perkembangan akal budinya tidak dapat lepas dari bahasa. 
Sigmund Freud (dalam Semiun, 2006:60) menyatakan manusia memiliki 3 susunan kepribadian, yaitu id, ego, dan super-ego. Id adalah bagian dari kepribadian yang awalnya disebut ketaksadaran, ego yaitu berisi penalaran dan pemahaman yang tepat, sedangkan superego adalah standar tentang benar dan salah yang mendasari sistem kontrol kepribadian. Superego mengandung dua bagian, yaitu suara hati dan ego ideal. Saussure dalam bukunya Course in General Linguistik mengatakan bahwa bahasa adalah suatu sistem tanda yang mengekspresikan ide-ide, pikiran, perasaan, benda atau tindakan dari pemberi tanda ke penerima tanda (sebagaimana dikutip Sibarani, 1992:2). Setelah melahirkan bahasa manusia dalam perkembangannya menghasilkan karya-karya sastra, sebagai tiruan dari segala aktifitas kehidupannya. Menurut Hartoko (1989:23) Sastra dapat dipandang sebagai suatu gejala sosial. Sastra yang ditulis pada suatu kurun waktu tertentu langsung berkaitan dengan norma-norma dan adat istiadat zaman itu. Karya. Sastra adalah suatu kegiatan kreatif sebuah karya seni.

Di dalam The American Collage Dictionary (dalam Tarigan, 1984:164) dijelaskan bahwa novel adalah suatu cerita prosa yang fiktif dalam panjang tertentu yang melukiskan para tokoh, gerak serta adegan kehidupan nyata yang representatif dalam suatu alur atau suatu keadaan yang agak kacau atau kusut. Berdasarkan uraian di atas karya sastra juga masih ada hubungannya dengan psikologi. Setiap individu pasti memiliki pengalaman dan jalan hidup yang berbeda. Pengalaman demi pengalaman yang dialami akan menimbulkan efek yang berbeda ketika mereka belajar sesuatu yang baru. Oleh Krauss (2005) manusia dianggap memiliki kecenderungan secara insting untuk memahami dan membuat makna terhadap kehidupan dan pengalaman mereka. Kennedy dan Kanthamani (1995) mengungkapkan bahwa dari 120 orang setidaknya tiap orang mempunyai satu pengalaman spiritual.

Khusus tanggapan masyarakat bisa dilihat dari animo pemberitaan dan pembuatan acara khusus di televisi yakni "indigo" pada kisaran tahun. Ada pihak yang peduli namun ada pula yang apatis dancenderung mempertanyakan keberadaan mereka. Lebih dari $80 \%$ dari anak-anak indigo yang dilahirkan sekarang adalah anak-anak indigo. Para indigo kita adalah anak-anak "keturunan baru", yang datang untuk mengubah dunia ini.

Penelitian ini juga membuka gerbang pemikiran tentang hubungan satra, indigo dan, otak kanan yang barubaru ini ramai dibicarakan. Membuka kunci untuk penelitian-penelitian berikutnya tentang hubugan indigo dan otak kanan. Otak kanan adalah otak emosional, yang erat kaitannya dengan Emosional Question (EQ), bersifat intuitif, spasial, visual, holistik, difus, paralel (literal), mencari persamaan dan tidak bergantung pada waktu (Santosa, 2008:1). Ciri-ciri inilah yang erat dengan ciri indigo, bukan tidak mungkin seorang indigo adalah orang yang otak kanannya lebih aktif dari pada otak kirinya. Selanjutnya baru-baru ini Ippo Santosa (2008: XXVIII-XXIX) dalam bukunya Wasiat Terlarang Dahsyat dengan Otak Kananmenyampaikan bahwa jika ingin sukses kita harus memulai dengan otak kanan, memulai segala sesuatu dari yang kanan, contohnya makan dengan tangan kanan. Burung garuda juga menoleh ke kanan, jarum jam juga bergerak ke kanan.Kultur Indonesia, Islam bahkan China dan Nasrani akrab dengan serentetan istilah serba kanan yang seluruhnya identik dengan kebaikan. 
Uraian singkat di atas yang penulis jadikan dasar penelitian. Novel yang menjadi obyek penelitian adalah novel Akar karya Dee Lestari.Serial Supernova ke -2 ini menjadi sesuatu yang menarik untuk dikaji. Kisah-kisah keindigoannya dan realismenya dalam kehidupan para indigo lainnya perlu dikaji untuk kekayaan ilmu pengetahuan.

Tujuan dari penelitian ini terbagi menjadi dua, tujuan umumnya yaitu mendeskripsikan fenomena indigo tokoh utama dalam novel Supernova episode Akar karya Dewi Lestari. Tujuan khususnya yaitu mendeskripsikan dan menjelaskan hal-hal yang berkaitan dengan fenomena indigo tokoh utama yang terdapat dalam novel Akar, yaitu: 1) Penggambaran kemampuan indigo pada tokoh dalam novel SupernovaAkar karya Dee Lestari. 2) Penyebab indigo pada tokoh dalam novel SupernovaAkar karya Dee Lestari. 3) Jenis indigo yang dialami tokoh dalam novel Supernova Akar karya Dee Lestari.

\section{METODE}

Pendekatan yang digunakan adalah melalui metode analisis kualitatif deskriptif. Penelitian kualitatif deskriptif adalah penelitian yang ditujukan untuk mendeskripsikan dan menganalisis fenomena-fenomena, peristiwa, aktivitas sosial secara alamiah (Sukmadinata, 2006:319). Tulisan hasil penelitian berisi kutipan-kutipan dari kumpulan data untuk memberikan ilustrasi dan mengisi materi laporan (Aminuddin,1990:16).

Sumber data primer dalam penelitian ini adalah novel Supernova Akar karya Dee Lestari. Data sekunder dalam penelitian ini yaitu data yang diperoleh dari internet, majalah, bukubuku, jurnal, novel serial Supernova lainnya dan hasil-hasil penelitian yang terkait dengan Indigo dalam novel
Supernova Akar Karya Dee Lestari: Kajian Psikologi Sastra.

Metode pengumpulan data dalam penelitian ini yaitu metode simak, sedangkan teknik yang digunakan yaitu teknik catat. Teknik analisis datanya adalah sebagai berikut: 1) membaca secara keseluruhan hasil transkrip data yang dilakukan oleh peneliti. 2) memberi kode atau kodifikasi pada data hasil penelitian kemudian memilih data sesuai dengan masalah penelitian, 3) mengklasifikasikan data indigo yang ditemukan dan dikumpulkan kemudian diidentifikasi serta diklasifikasikan berdasarkan masalah penelitian, 4) mendeskripsikan setiap data yang diperoleh dengan kalimat yang tepat sesuai dengan batasan peneliti yang telah ditentukan dalam rumusan masalah,dan 5) menganalisis data yang telah dideskripsikan dalam pembahasan untuk menemukan hasil dari penelitian atau simpulan.

\section{HASIL DAN PEMBAHASAN Indigo}

Sigmund Freud (dalam Semiun, 2006:60) menyatakan manusia memiliki 3 susunan kepribadian, yaitu id, ego, dan super-ego. Id adalah bagian dari kepribadian yang awalnya disebut ketaksadaran, ego yaitu berisi penalaran dan pemahaman yang tepat, sedangkan superego adalah standar tentang benar dan salah yang mendasari sistem kontrol kepribadian. Superego mengandung dua bagian, yaitu suara hati dan ego ideal. Suara hati merupakan bagian superego yang bersifat menghukum, negatif dan kritis yang mengatakan apa yang tidak boleh dilakukan dan menghukum dengan rasa bersalah jika melanggar tuntutannya. Ego ideal terdiri dari aspirasi positif, misalnya ketika anak ingin menjadi pelukis terkenal, maka pelukis terkenal adalah ego idealnya. Ego ideal bisa juga 
bersifat abstrak seperti keinginan untuk menjadi lebih murah hati, berani, disiplin, atau berdedikasi tinggi bagi prinsipprinsip keadilan dan kebebasan.Berdasar teori tersebut Bodhi sebagai tokoh utama dalam novel ini juga memiliki susunan kepribadian id,ego, dan super ego yang terwujud dalam indigo yang dia alami. Indigo ini menurut berbagai pemikiran mempunyai kesamaan ciri dengan indera keenam.

Menurut Arter (2017:13-14) kemampuan indera keenam meliputi : 1) Teleportasi, adalah kemampuan untuk memindahkan suatu objek dari satu tempat ke tempat lain tanpa perlengkapan alat fisik. 2) Telekinesis, adalah sebuah kemampuan yang bisa dimanfaatkan untuk memengaruhi pikiran beberapa orang di sebuah lingkungan dengan menggunakan kekuatan doa,batin dan pikiran yang disugesti kuat. 3) Telepati adalah kemampuan berkomunikasi antara satu pikiran dengan pikiran lain. 4) Levitasi, yaitu kemampuan untuk meringankan berat benda agar mudah diangkat atau dipindahkan ke suatu tempat. 5) Clairvoyance, adalah kemampuan menangkap dan menganalisis kilasan gambaran yang biasanya hadir dalam pikiran dan batin. 6) Clairsenteince, adalah perasaan tidak nyaman dalam batin seseorang, baik ketika menemukan hal baru atau berhadapan dengan orang lain. 7) Clairaudience adalah bisikan atau suara batin yang berasal dari kekuatan di luar batas. 8) Psychometri adalah kemampuan untuk mendapatkan data dari benda mati atau kemampuan untuk mengetahaui informasi melalui benda yang berkaitan dengan persoalan. 9) Procegnition adalah kemampuan untuk melihat suatu kejadian untuk melihat suatu kejadian di masa depan. 10) Retrocognition adalah kemampuan untuk mengetahui rincian tentang sesuatu yang telah terjadi di masa lalu tanpa pernah diberitahu atau membaca tentang hal itu. 11) Mediumship adalah kemampuan indera keenam yang dihubungkan dengan sebuah sistem spirit di luar diri kita.

Penyebab indigo menurut Nurfaidah dalam jurnal Refleksi anak indigo dalam Perempuan Mencari Tuhanmengatakan menyatakan, penyebab munculnya anak indigo bisa terjadi karena beberapa hal, antara lain : 1) Berasal dari keturunan yang masih memberlakukan syirik, misalnya menyimpan keris yang dianggap memiliki berkah, atau memelihara benda pusaka lainnya. 2) Turunan dari kakek, atau ada keluarga yang juga indigo. 3) Tidak turunan, tetapi jin mencoba menggoda anak tersebut.

Di buku yang lain penyebab seseorang menjadi indigo menurut Arter (2007:14) menyatakan indigo atau indera ke enam bisa merupakan anugerah karomah yang diberikan Alloh kepada manusia yang dikehendaki. Selain itu indigo atau indera ke enam adalah suatu keistimewaan yang sebenarnya sudah ada yang hanya perlu di asah agar lebih tajam, juga bisa diupayakan dengan tehnik-tehnik tertentu.

Jenis indigo menurut Carrol \& Tober membagi indigo menjadi 4 macam, yaitu ;1) Humanis, yaitu memiliki perikemanusiaan tinggi. 2) Konseptual, yaitu lebih tertuju pada sebuah proyek dari pada manusia. 3) Seniman atau artis, yaitu tertuju pada seni dan kreatif. 4) Interdimensional, yaitu lebih banyak mengalami peristiwa ESP dibandingkan tipe yang lain.

\section{Penggambaran Kemampuan Indigo Tokoh \\ Mempunyai kekuatan fisik yang luar biasa (Levitasi)}

Anak indigo yang melakukan kegiatan fisik yang banyak dan terlalu 
kuat akan mengalami gangguan karena tubuh mereka sensitif(Virtue, 2011: xix). Kemampuan Bodhi diantaranya; mempunyai kekuatan fisik yang luar biasa yang tidak dimiliki oleh manusia biasa. Suatu kali dalam acara pertunjukan musik Bodhi jatuh ke tanah dari tempat yang sangat tinggi, tetapi anehnya tak ada luka atau lebam sedikitpun di tubuhnya, hal ini terbukti dalam kutipan :

"Sampai akhirnya, pada loncatanku yang kesekian, aku begitu tenang. Aku melayang. Sempurna seperti Superman. Jauh, jauuuh...........sekali rasanya. Dan, ketika mataku membuka, tangan-tangan itu tak ada. Cuma tanah. Badanku jatuh dengan suara debup keras" (Lestari,2012:30).

Kemampuan seperti itu termasuk dalam levitasi, jangan heran apabila ada seseorang yang bisa berjalan di atas air dengan santai dan tenang (Arter, 2017:28-29).

\section{Bisa melihat atau merasakan kejadian di masa depan (Procegnition)}

Seorang indigo atau anak indigo memiliki intuisi yang tinggi, karena anak indigo dianggap memiliki kemampuan menggambarkan masa lalu dan masa datang (Virtue, 2011: xxiv).Suatu ketika tempat Bodhi dan Bong serta temantemannya kebakaran. Kebakaran yang tidak diketahui apa penyebabnya. Kejadian tersebut terjadi pada jam-jam siaran, logikanya Bodhi akan ikut terbakar saat siaran. Tapi saat terjadi kebakaran itu Bodhi tiba-tiba tidak siaran, yang hal bolos kerja seperti itu hampir tidak pernah dilakukan, sehingga Bodhi selamat tidak ikut terbakar. Terbukti dalam kutipan berikut :

"Bong, kenapa gue di sini ya? Gue mestinya pergi siaran. Tapi,kog ? Ia memotongku dengan tawa ngakak, "Lo memang bangsat yang beruntung! Gudang kita kebakaran gede-gedean barusan. Ba-ru-san! Bentar lagi matang, kali. Pemadam kebakaran saja belum sempat datang. Gue baru dapat kabar dari si Nyong," lanjutan kalimat Bong lenyap ditelan ruang kosong" (Lestari,2012:25)

Penemuan kedua dari penggambaran kemampuan tokoh Bodhi adalah dapat mengetahui atau merasakan kejadian yang akan terjadi di masa depan pada alam bawah sadarnya.

\section{Bisa merasakan yang tidak terlihat atau yang tidak dilihat orang lain (Psicometri)}

Mereka lebih banyak menggunakan pusat visual otak mereka daripada paruh otak yang merupakan pusat logika (Virtue, 2011:181). Dalam beberapa kisah pada novel Akar, Bodhi mengalami hal-hal luar biasa yang tidak dirasakan oleh orang lain. Suatu ketika saat dia berjalan di atas lantai, tiba-tiba lantai itu berubah menjadi pusaran api. Terbukti dalam kutipan berikut :

"Dunia yang tertangkap panca indera saya ternyata beda dengan orang lain. Kadang-kadang, saya harus jalan sambil terus meraba tembok supaya bisa tetap mengukur dimensi panjang-lebar-tinggi, Sesuatu yang kalian lakukan tanpa usaha. Ketika lantai yang saya pijak mendadak hilang dan berubah menjadi pusaran api, saya bingung mana yang harus saya percaya; mata atau jari kaki ? merem juga percuma"'(Lestari,2012 :41)".

Dari uraian di atas, dapat diketahui penggambaran kemampuanpsicometri yang dimiliki Bodhi adalah kemampuan yang agak unik dibanding kemapuankemampuan indigo sebelumnya.

Bisa memindahkan obyek dari satu tempat ke tempat yang lain tanpa perantara perlengkapan alat fisik (Teleportasi)

Beberapa anak indigo menunjukkan kemampuan yang lebih dalam bidang seni untuk mengekspresikan kreativitasnya, seperti menari, melukis, menulis, atau keterampilan lain dengan 
usaha yang besar (Virtue, 2011: xix).Keindigoan Bodhi yang dirasakan sejak kanak-kanak beranjak dewasa menjadi berkembang, tidak hanya bisa melihat benda yang tidak bisa secara kasat mata, tapi dia juga bisa memisahkan roh dari jasadnya sendiri. Terbukti dalam kutipan :

"Beranjak remaja, pengalaman aneh itu berubah tipe. Bukan lagi pemandangan yang seram-seram, tapi sepertinya tubuhku mengejar pengalaman yang lebih terpadu. Suatu hari, ketika selesai meditasi sambil berbaring, aku bangkit duduk dan badan ini tidak ikut. Waktu itu aku merasa yakin sudah mati karena lama-lama sensor atas dunia, realitas fisik ini, hilang. Semua yang kulihat bergerak cepat sesuai gerak pikiran" (Lestari,2012:43).

Ini terjadi dalam sebuah meditasi yang ia lakukan sebagai seorang Budha. Hal ini berkali-kali dialami Bodhi.

\section{Bisa merasakan apa yang dirasakan} oleh orang yang dilihat (Clairvoyance)

Anak indigo sensitif terhadap situasi dan orang yang ada di sekitarnya. (Virtue, 2011:85).Clairvoyance adalah kemampuan menangkap dan menganalisis kilasan gambaran yang biasanya hadir dalam pikiran dan batin. Bisa merasakan apa yang dirasakan orang lain,bahkan dalam tingkatan yang lebih tinggi bisa berubah wujud menjadi apa yang dipandang.Bodhi juga memiliki kemampuan seperti di atas,terbukti dalam kutipan:

"Fase berikut, yang menurut saya paling parah, yaitu ketika diri saya berubah identitas. Makudnya begini, tahukah kalian bagaimana rasanya jadi tikus got? kucing? bahkan lalat? saya tahu. Lalat adalah pengalaman pertama. Hari itu ada seekor lalat hinggap di atas nasi yang sedang kumakan. Aku Cuma melihatnya sekilas sebelum mengibas, dan tahu apa yang terjadi? mendadak kepalaku kesemutan, seperti diremas dan dibawa lari. Tiba-tiba, dunia jadi kabur, berpendar, dengan warna-warna menyala yang aneh, aku tak mengenal apapun yang kulihat. Kata-kata hilang, tinggal rasa, lapar, takut. Sesaat kemudian, semuanya lenyap lagi, dengan sensasi kesetrum yang sama. Tadinya aku tak yakin apa artinya. Aku baru sadar ketika bertatapan lagi dengan lalat itu, yang masih diam. Namun, kali ini aku melihat diriku dalam dirinya " (Lestari,2012:44).

\section{Penyebab kemampuan indigo tokoh}

Keistimewaan yang diberikan Tuhan kepada hamba-Nya yang Dia kehendaki

Indigo atau indera ke enam bisa merupakan anugerah karomah yang diberikan Alloh kepada manusia yang dikehendaki (Arter, 2007:14). Dalam penyebab kemampuan indigo yang dimiliki tokoh Akar ini, peneliti bisa merumuskannya sebagai karomah, hadiah keistimewaan yang diberikan oleh Allah Tuhan maha pemberi. Sebagai karuniaNya yang diberikan tanpa pilih kasih, sebagai rasa sayangnya kepada semua makhluk-Nya.Hal tersebut terbukti dalam kutipan berikut :

"Ketika aku mulai besar, Guru Liong baru bercerita bahwa peristiwa itu sudah diketahui lewat mimpi kira-kira dua tahun sebelumnya dan berulang terus setiap hari pada seminggu terakhir sebelum aku ditemukan. Dalam mimpinya, ada sebuah pohon bodhi betulan menaungi satu peti besar berisi cahaya. Ketika Guru Liong mengintip ke dalam peti, tiba-tiba cahaya itu menjelma menjadi bayi yang sudah bisa berjalan dan bicara. Seperti kisah Siddharta Gautama. Bayi itu lalu melayang di atas tanah dan membakar pohon tadi dengan jarinya. Yang lebih gila lagi, semenit sesudah Guru Liong mengambil dus rokokku, pohon asam tadi disambar petir. Hangus seperti batang korek terbakar"(Lestari,2012:39).

Turunan dari pendahulu atau nenek moyang 
Penyebab indigo menurut Nurfaidah dalam jurnal Refleksi anak indigo dalam Perempuan Mencari Tuhan mengatakan menyatakan, penyebab munculnya anak indigo bisa terjadi karena beberapa hal, antara lain : 1)Berasal dari keturunan yang masih memberlakukan syirik, misalnya menyimpan keris yang dianggap memiliki berkah, atau memelihara benda pusaka lainnya. 2) Turunan dari kakek, atau ada keluarga yang juga indigo.Keistimewaan Bodhi mungkin juga karena turunan, dari nenek moyang Bodhi atau keluarga terdahulu yang lain, karena dari penjelasan novel Akar, Bodhi adalah yatim piatu tidak diketahui asal usul orang tua Bodhi. Dari mana dia berasal siapa nenek kakeknya, bapak ibunya tidaklah diketahui. Disebutkan dalam kutipan berikut :

"Guru Liong menemukanku di halaman depan wihara, terbungkus sarung, dalam kotak kardus rokok bekas yang diletakkan di bawah pohon. Subuh-subuh. Dua puluh tiga tahun lalu” (Lestari,2012:38).

Begitulah dari bukti dan teori pendukungnya,dapat disimpulkan bahwa penyebab kemampuan indigo Bodhi adalah turunan dari pendahulunya atau nenek moyangnya.

\section{Diperoleh dari usaha atau latihan}

Menurut Arter (2017:16), kemampuan indigo atau indera keenam tersebut selain merupakan karomah yang diberikan Allah, kepada manusia khusus yang dikehendaki, kemampuan tersebut juga bisa diupayakan dengan usahausaha.

Kemampuan-kemampuan tokoh Bodhi dalam novel Akar ini mungkin juga karena ritual-ritual yang dilakukan Bodhi sebagai seorang Budha. Selama 18 tahu di wihara, Guru Liong yang seorang biksu mengajarinya berbagai macam ritual dan doa. Bukti dalam kutipan :
"Om Ram/Om Svar?Namo Saptanam Samyaksambudda Kotinam Jita?Om Jarah Wajra Kundhi Svaha/Om Bhur/Om Mami Padme Hum, aku merapal mantra, mataku membuka menemukan empat anak itu ternganga. Aku tersenyum kecil." Itulah mantra Bodhisattva Tangan Seribu. Bukan jampi-jampi. Jangan merasa terintimidasi. Saya tidak menyuruh kalian menirukannya. Ini hanya syariat saya, ritual yang selama delapan belas tahun saya jalankan di wihara"(Lestari, 2012:37).

Selama 18 tahun Bodhi menghabiskan waktunya di wihara.Tak heran jika Bodhi banyak melakukan ritual yang lebih bisa dilakukan oleh orang yang tinggal di luar tempat suci.

\section{Jenis kemampuan indigo tokoh Indigo Humanis}

Sesuai dengan pengertian dari humanis menurut Carrol dan Tober ,yaitu memiliki perikemanusiaan tinggi. Pada suatu saat Bodhi diminta untuk menjadi pengasuh dalam sebuah acara yang diadakan oleh rumah singgah untuk anakanak punk, maka Bodhi dengan senang hati menerima permintaan itu. Terbukti dalam kutipan :

"Syukur Bong menyadarkanku. " Bod, lo ditunggu sama anak-anak entar sore. Program orientasi lagi. Bisa, kan?"

'Bisa," aku mengangguk. Sekalipun status manusiaku diragukan, tetapi minimal aku masih punya guna untuk manusia lain" (Lestari,2012:27).

\section{Indigo Artistik}

Anak indigo biasanya sangat artistic dan otak kanan mereka dominan. Hasil karyanya biasanya kearah spiritual, contoh : membuat sajak yang isinya spiritual (Carroll (2006:90). Indigo yang dialami tokoh Bodhi dalam novel Akar, dia juga memiliki karakteristik yang dpat dikategorikan dalam indigo artistik. Hal ini terbukti dalam kutipan : 
"Kell tersenyum, cepat dan sekilas bagai tanpa kedip mata. Dengan punggung tangannya, ia mengusap stensil tato yang kugambar untuk Star. "Tree of Life," ia berbisik untuk dirinya sendiri, "saya tidak pernah punya murid sebelumnya, tapi bisa saya pastikan kamulah yang terbaik. I'd give you an 8,5 for this one. Gambarmu bahkan lebih baik dari saya" (Lestari,2012:109).

\section{SIMPULAN}

Berdasarkan hasil analisis yang penulis lakukan dalam meneliti fenomena indigo yang dialami tokoh Bodhi dalam novel Supernova Akardengan menggunakan kajian psikologi sastra, penulis dalam bagian ini dapat menyimpulkan tiga hal penting yang menjadi pokok kajian dalam penelitian ini, yaitu: Kemampuan Bodhi diantaranya; 1) mempunyai kekuatan fisik yang luar biasa yang tidak dimiliki oleh manusia biasa,2) bisa melihat atau merasakan kejadian di masa depan ( Procegnition), 3) bisa merasakan sesuatu yang tidak terlihat dan tidak dilihat orang lain (Psicometri), 4) bisa memindahkan suatu objek dari satu tempat ke tempat lain tanpa perantara perlengkapan alat fisik (Teleportasi), 5) bisa merasakan apa yang dirasakan oleh orang yang dilihat (Clairvoyance).

Dari berbagai pemikiran yang disebutkan di atas penyebab keindigoan tokoh Bodhi pada novel Supernova Akar yaitu; 1) sebuah keistimewaan yang diberikan Tuhan kepada hamba-Nya yang Dia kehendaki. Kemampuan indigo diberikan Tuhan kepada Bodhi tanpa alasan yang kita tidak wajib tahu. 2) Keistimewaan Bodhi mungkin juga karena turunan, dari nenek moyang Bodhi atau keluarga terdahulu yang lain, karena dari penjelasan novel Akar, tidak diketahui asal usul orang tua Bodhi. 3) Diperoleh dari usaha atau latihan.
Kemampuan-kemampuantokoh Bodhi dalam novel Akar ini mungkin juga karena ritual-ritual yang dilakukan Bodhi sebagai seorang Budha

Mengenai penjenisan indigo, tokoh Bodhi dalam novel Akar tergolong dalam indigo humanis. Sesuai dengan pengertian dari humanis menurut Carrol dan Tober ,yaitu memiliki perikemanusiaan tinggi. Dia juga memiliki karakteristik yang dapat dikategorikan dalam jenis indigo artistik, yaitu menjadi seorang ahli tato yang profesional, bahkan lebih baik dari yang mengajarinya.

\section{DAFTAR PUSTAKA}

Ahmadi, Abu. 2009. Psikologi Umum. Jakarta:Rineka Cipta.

Aminuddin.1990. Sekitar Masalah Sastra. Beberapa Prinsip dan Model Pengembangannya. Malang: Asuh (YAA) Malang.

Arter, Derry. 2017. Tips Trik meningkatkan dan menajamkan Indera Keenam. Yogyakarta: Arsaka

Bahri. 2010. Terapi Bermental Sukses. Jakarta: RMBOOKS

Carroll, L., \& Tober, J. 2006. The indigo children. Jakarta: Bhuana Ilmu Populer.

Lestari, Dee. 2012. Akar. Yogyakarta: Bentang Pustaka.

Musthofa. 2010. Khusu' Berbisik-bisik dengan Allah.Surabaya:PT Patma press

Rhine, JB. 1997. Ekstra Sensory Perception. (e-book). Internet: Google Books.

Santosa. 2008. Wasiat Terlarang Dahsyat Dengan Otak Kanan. Jakarta: PT Gramedia

Semiun, Yustinus. (2006). Teori Kepribadian dan Psikoanalitik Freud. Yogyakarta: Kanisius. 